\title{
American regional science school contribution to South Korean regional development management system
}

\author{
Olga Kuznetsova ${ }^{1, *}$, Liubov Lebedintseva ${ }^{2}$, Evgeny Kremnyov ${ }^{1}$, and Violetta Korobko ${ }^{1}$ \\ ${ }^{1}$ Irkutsk State University, Department of Oriental and Asia-Pacific Studies, 664000, Irkutsk, Russia \\ ${ }^{2}$ Saint Petersburg State University, Department of Economical Sociology, 199226, Saint Petersburg, Russia
}

\begin{abstract}
The authors of this article, using the approach of transdisciplinary regionology, consider how the formation of regional studies in the Republic of Korea took place. According to the authors, this process was significantly influenced by the United States, a country that is the ancestor of regional science. The article lists several factors that influenced the fact that the regional studies in Korea began to be carried out exactly according to the American model. There are examples of original American concepts that are actively used by Korean scientists at present. In addition, the authors attempt to highlight the distinctive features of the South Korean approach to regional studies.
\end{abstract}

\section{Introduction}

In the XXI century, scientists have a fairly extensive arsenal of methods for conducting regional studies; the approaches to research of this kind vary within different scientific schools, which often causes significant difficulties, including terminological ones. Thus, the authors of this article have attempted to define the structure of regional knowledge in different foreign schools [1].

The influence of certain scientific schools on the development of regionology in other regions is the question of particular interest. What factors allow the school of a particular country to dictate the directions of the development of world regional thought? Do the borrowed approaches from other scientific schools transform under the influence of specific regional characteristics? Under what conditions does the dominant approach change? Currently, issues of this kind are in the focus of attention of regional studies specialists around the world.

The purpose of this article is to study the process of penetration and transformation of approaches to regional studies on the example of two highly developed countries - the United States and the Republic of Korea. It is noteworthy that the selected countries are vivid examples of different cultures - western and eastern, located at a considerable distance from each other, which, nevertheless, hasn't prevented the active dissemination of American regional science among representatives of the Korean scientific community.

The research is carried out in line with the concept of transdisciplinary regionology that is developed by the authors [2].

\section{Results and Discussion}

\subsection{The origin of regional science in the USA}

Undoubtedly, it would be erroneous to say that regional studies have appeared in the United States; earlier works of this kind were found in large numbers among European scientists, who had a decisive influence on the formation of this scientific direction in the young North American state. The history of regional studies has been encompassing more than one century, but in the middle of the XX century the idea of the need for a separate scientific discipline studying regions (regional science) finally took shape. An outstanding American regional studies specialist Walter Izard is considered to be the founder of this concept.

It is important to say that the ground for the emergence of a new scientific direction has been prepared in the United States in a relatively short period, which has reflected both a significant increase in interest in the humanities in general and the emergence of an awareness of the need to form an interdisciplinary approach to the regional studies.

In «An Introduction to Regional Science», W. Isard gives 13 definitions of regional science, however, according to the scientist, "it is clear from the diversity of definitions that no single one can be considered the best or most complete. Each researcher and student will need to develop or synthesize his definition after having read this book and other studies" [3]. However, when analyzing all the definitions, we can easily deduce common features - they all emphasize the interdisciplinarity of the new science. Indeed, modern regional science unites economists, geographers, 
planners, architects, engineers, environmentalists, sociologists, political scientists, psychologists, lawyers, and other scientists - representatives of all branches of knowledge who consider it necessary to study the regional context when solving professional problems. The economic component prevails in Izard's regional science, which is explained by some reasons: firstly, the scientist himself was an economist by education, and secondly, the main national interests during the emergence of regional science included the study of the economic potential of various regions of the country.

\subsection{Factors that have increased the influence of the American regional school on South Korean studies}

In our opinion, Korean scientists did not take a particularly active part in the institutionalization of regional science. They considered this new direction rather "suitable for use" and effective for stimulating the economic development of the country. It seems possible to us to identify several factors that have influenced the formation of regional thought in the Republic of Korea that has taken place under the significant influence of the American school.

1) First of all, it is impossible not to note the influence of the American school and Isard personally on the popularization of the idea of a complex study of regions around the world. In the summer of 1960, the scientist began to take active steps to spread regional science in Europe - where, as already mentioned earlier, regional studies have been carried out for several centuries, but this mainly took place within the framework of individual humanities disciplines. By 1962, Isard's ideas had spread to the Latin American region and the Far East. In 1962 the Japan Section of the Regional Science Association was formed, which began to develop quite actively, and the first Far East Conference was held in September 1963 [4]. The Korean Regional Science Association was founded much later - on August 22, 1983; it is noteworthy that W. Isard himself was present at the organizational meeting.

2) Notoriously, the study of Korea like a sphere of area studies has been ignored in Western countries for a long time. We can say that the active exchange of scientific knowledge between Korea and the West has begun relatively recently - in the middle of the XX century. Due to the strengthening of its position in the world geopolitical arena after the division of Korea into North and South parts in 1945, it was the United States that had the opportunity to participate actively in the development of the new state - since the 1950s, the United States has begun to take an assertive part in providing economic assistance to South Korea.

3) During the same period, the Americans were actively engaged in advising Korean specialists on economic issues.

According to Karl Moskowitz, who held the post of the representative director of Korea Institute at Harvard in the 1990s, American economists and development specialists trained a generation of Korean economists; the process of studying was supported by works from a field of American regional school.

Naturally, American scholars have dominated the analysis of Korea's economic development. Even more, the other principal group studying Korean development was Korean economists trained in the United States.

Therefore, the first scientific project on the analysis of the features of the economic development of South Korea was implemented by American and Korean scientists. The American group was headed by economist Edward Sagendorf Mason, founder of the Development Advisory Service in 1963, later renamed the Institute for International Development at Harvard. In the early $1970 \mathrm{~s}$, both groups joined together to conduct a comprehensive analysis of the recent development of Korea [5].

The objective of the research project was nothing less than to examine the elements underlying the remarkable growth of the Korean economy and the distribution of the fruits of that growth, together with associated changes in society and government; and to evaluate the importance of foreign economic assistance, particularly American assistance, in promoting these changes. Dozens of development specialists - not only economists but also eminent scholars in demography, education, and urbanization undertook significant research responsibilities.

4) One more reason for such close scientific cooperation was represented in awareness of Americans in their insufficient knowledge about Korea. The researchers have found themselves perforce delving into complex questions of historical, sociological, and political nature to a greater extent than perhaps they anticipated. Only a few of the American participants have been able to read and speak Korean and; in consequence, the collaboration of their colleagues in making Korean materials available has been invaluable [5].

It seems possible to say that during this project, a new tradition was born, and it continues to this day - Western scientists who are engaged in Korean studies, but do not know the Korean language or the history of the country, ask Korean colleagues to act as "experts" on Korea.

5) The phenomenon of scientific migration, which began to spread actively from the second half of the XX century, influenced the dominance of American approaches to regional studies in Korea. In this case, we consider it possible to say that this has led to an increase in interest in studying Korea beyond its borders. Numerous Korean scientists who started working at the departments of American universities chose the most familiar region - Korea as the object of their regional studies, and, consequently, their American colleagues have also learned more about this region. And currently, many scientific articles on regional studies are written by Koreans in English in collaboration with Western scientists.

\subsection{Modern strategies of regional development in the Republic of Korea created under the American school influence}


At this moment, regional studies are still in the focus of attention of Korean specialists who are actively engaged in examining the following topical issues:

- sustainable development of cities;

- state policy on the better organization of the space and achievement of regional development;

- relationship between urbanism and ecology;

- features of urban planning to achieve sustainable development and urban regeneration;

-stimulating regional development through the introduction of innovative scientific development, etc.

It is important to note that when analyzing the works of modern Korean scientists, we can trace the influence of American approaches to solving regional problems and studying regions. Of course, the format of the article does not allow us to consider all the available examples; we will give only a few of them.

1) For example, in South Korea, there are extremely common studies in which the level of development of high technologies acts as a decisive factor stimulating the economic development of the region. In the vision of Oh Deog-Seong, the author of numerous works on urban planning and professor of Chungnam National University, Daejeon, an effective way to increase the level of high-tech development in the region is to create high-tech centers. In the scientist's understanding, a "high-tech center" is a specific urban building that sometimes appears during urban replanning, the purpose of which is to attract high-tech industries, universities, research labs. There are two types of centers - science parks and technopolises [6].

An example of the implementation of this strategy is the creation of a Science Town in Daedeok (from 1973). Now, this scientific cluster consists of more than 20 large research institutes and more than 40 corporate research centers. Over the past few years, several venture IT companies emerged in this region, in which there is a high concentration of $\mathrm{PhDs}$ in the field of Applied Sciences. It is essential to say that the experience of the development of technopolises in the USA and Japan was taken as a basis.

As known, the homeland of technology parks is considered to be the United States, where in the early 1950s the first Stanford Research Park was organized, which has marked the beginning of the famous Silicon Valley. It is the largest in the United States and the most famous technology park in the world that produces $20 \%$ of the world's computing equipment and computers.

The topic of technology parks is actively being developed in the United States at present time. As an example, we will cite the research of Anna Lee Saxenian, a professor at the University of California at Berkeley, known for her work on technological clusters and social networks in Silicon Valley. She explains the success of this technology park in the development of the high-tech industry by the fact that production networks are used there. Although both Boston's Route 128 and Silicon Valley were centers of high technology in electronics in the 1970 s, only the latter managed to cope with the regional recession in the 1980 s and become an international leader in the high-tech industry.
When studying the reasons for the two different growth trajectories, Saxenian concludes that the differences, first of all, lie in the essence of the structure of an industry in the two regions. Silicon Valley production was characterized by dense social networks based on flexible specialization. Route 128 , on the contrary, was controlled by a small number of hierarchically integrated corporations, where privacy and independence were valued [7].

2) Much attention is paid in South Korea to the creation and implementation of strategies to achieve balanced regional development. It is worth mentioning that the central government takes a dominant role in economic and spatial development, for example, by the introduction of three consecutive ten-year Comprehensive National Land Development Plans from 1972 to 2011. These plans have contributed to the expansion of the physical infrastructure and the improvement of the social and economic situation of Korea. And already in their text, there is an idea about the necessity to choose optimum locations (growth poles) and the expansion of physical infrastructure for industrial and urban development [8].

The same Growth Poles Theory has formed the basis of a strategy to reduce regional disparities, the essence of which is to create innovative cities not in the capital regions to reorganize the existing, regionally unbalanced, national spatial structure. Such cities have their characteristics and functions, and among the positive effects of their creation, experts note the following:

- decentralization of administrational functions;

- alleviation of population growth in the capital region;

- improvement of regional innovation capabilities;

- growth of regional economies [8].

Since 2005, ten innovative cities have been constructed in Korea, about one for each province, and the government invested $\$ 9.5$ bn in this initiative. An innovative city is a sort of growth pole that generates and spreads the innovation to its neighboring areas through innovative clusters. During the construction of cities, three components were clustered: research institutes, universities, and public institutions [9].

Speaking about the Growth Pole Theory we should note that it was the American economic school that made a significant contribution to its development; it was represented by economists Albert Hirschman and Milton Friedman. Thus, Hirschman suggested that polarized development could benefit both the growing region and the surrounding hinterland. The scientist has come up with an idea that growth in a developed region produces favorable «trickling-down» effects within a lagging region as the lagging region's goods are purchased and labor hired by the developed region. At the same time, growth may produce unfavorable "polarization" effects resulting from competition and trade barriers erected by the developed region [10].

In 1966, M. Friedman put forward a similar idea - the center-periphery model. The economist also has pointed out that regions may vary in the extent to which supply constraints limit a region's ability to respond to increased demand for exports. In his opinion, large urban 
areas have the initial advantage in the competition for new growth because of the decreasing cost benefits of urbanization economies. Thus, all these factors tend to work to the advantage of core regions. Outside of the core, regions are differentiated by their relative degree of regional economic autonomy. Besides core regions, Friedman highlights «resource frontiers» - undeveloped regions whose primary draw is the plentiful supply of untapped natural resources, as well as «downwardtransitional areas» - rural areas trapped in a stage of structural poverty, primarily due to their structural dependence on adjacent core regions [11].

3) Generally, the transition from the regional to the global component is noticeable in modern Korean regional studies. The majority of university educational programs on regional issues are united by the approach of connecting the study of global world processes, whether economic, cultural, or political, with Korean studies and the place of Korea in the world, its possibility of successful integration into the global community.

If we analyze the websites of the leading faculties engaged in training specialists on regional problems, it becomes obvious that they see their mission in training specialists who are citizens of the world, capable of solving global issues, and well-versed in the global problems of the world community.

In addition, plenty of scientists study the phenomenon of globalization and its impact on the development of regions. So, Kim Yong Woong and Cha Mi Sook, employees of the Korea Research Institute for Human Settlements (Seoul), seek to define which spatial development strategies are more efficient to apply in the era of globalization.

According to the specialists, the globalization of the economy is an irreversible and inescapable trend precipitating fundamental transformation in the overall socio-economic system. The biggest strategic issue for Korea is effective adjusting to future changes.

Since globalization is accompanied by overall changes in socio-economic organizations and structures, it will be difficult to single out the impacts of globalization and try to meet them individually [12].

Therefore, spatial policy and planning need to be more concerned with improvement in the quality in various aspects of urban and regional development rather than improvement in a few particular areas. It should put more emphasis on the creation of institutional or organizational frameworks to promote technological innovation, new firm formation, and local networking for information. It should be one of the major tasks for spatial development policy to create an adequate sociocultural environment, such as high-quality social services, community facilities, and a cultural environment to meet with a globalized society.

The constantly changing nature of regional science is a sufficiently common topic among the works of American regional studies specialists. Thus, the American geographer Lay James Gibson, together with his French colleague Antoine Bailly, says that the disciplines of physics, French, or economics change over time, but they remain physics, French or economics.
Regional science is unique in that it is continuously reinterpreted. The specialists highlight three periods for regional science:

- thinking regionally,

- thinking globally,

- thinking sustainable.

Regional science received a boost from the events following the Second World War; spatial scientists as planners and managers were in demand. The 1950s, 60s, and 70s were good years for regional science, but in the 1980s, "thinking regionally" was replaced by "thinking globally". Respectively, there was the closure of some departments friendly to regional science, and in their place, numerous programs and approaches in global studies have been undertaken. At this moment, the sustainable development concepts, widely developed by regionologists around the world, are becoming increasingly popular [13].

\subsection{Distinctive features of Korean regional studies}

Even though Korean scientists actively use the accumulated western experience in their developments, we can also emphasize what discerns Korean studies from many others. First of all, this is about the fact that regional studies are often identified with Korean studies in the minds of Koreans.

Let us explain that initially, Korean experts were considered foreign specialists engaged in the study of Korea. Korean scientists preferred to name themselves linguists, sociolinguists, historians, but not Korean experts.

The exceptions were cases when Korean scientists received education overseas and published their scientific works not only in Korean, but also in other languages, primarily in English. In the mid-2000s, one of the trends in higher education in Korea was an increase in the number of university disciplines taught in English, which resulted in the fact that a lot of Korean scholars who studied abroad were hired at Korean universities.

At this moment there are plenty of institutions in the Republic of Korea that are engaged in the preservation and distribution of Korean culture. For example, "Academy of Korean Studies" considers Korean studies as a complex study of Korea, its history, philosophy, literature, folklore, politics, sociology, as well as the Korean language. It should be noticed that great attention is paid to the study, analysis, and interpretation of Korean culture. Given section is understood by specialists widely, and in some cases, the terms "Korean studies" and "Korean cultural studies" are used as synonymous [14].

We have analyzed the overwhelming majority of the works of Korean authors that are devoted to the study of Korea as a region of the greatest interest. Large units such as The Korean Studies Institute and "Korea Foundation" are also targeted at promoting Korean studies around the world, distributing information about Korea, and preserving the country's cultural heritage. 
Such aspiration aiming to preserve its culture can be easily explained by the historical peripeteias of this country - a long period of isolation and not flattering estimation from the West, which has considered Korea a "recluse country" and a "barbarian country", a period of colonialism, in which Japan's policy has initiated distinct attempts to destroy Korean culture, the idea of "Koreacentrism" that arose on the peninsula quite a long time ago. The Republic of Korea sees the promotion of the Korean direction as one of the foreground goals in the development of regional studies. The most common educational program for regional studies is "Korean Studies" or "World Korean Studies".

\section{Conclusion}

Bruce Cumings, a famous American historian, and specialist on East Asian countries, sees the reason for South Korea's rapid economic success in a special regional phenomenon, under which he assumes at first great attention from Japan, and then from the United States [15]. In our opinion, in the field of regional studies, the country has elected the "borrower" model from the developed scientific approaches. Nevertheless, it is worth noticing the striving and readiness of Korean scientists to test and transform borrowed methods and approaches. Not by chance, the Republic of Korea has been occupying a leading position in the rating of innovative countries for a long time. Innovation is one of the main topics of Korean regional studies: the construction of technopolises, the creation of innovative cities, etc.

We have also noticed the role of the external context in the strategy of training Korean scientific personnel. It is about the fact that many Korean specialists in regional studies in the XXI century receive professional education in Western countries, first of all, in the United States, which, naturally, leaves a certain print on the formation of their scientific picture of the world. The phenomenon of scientific migration, which has begun to spread actively since the second half of the XX century, also influenced the predominance of Western approaches to regional studies in Korea.

However, the idea of preserving Korean traditional culture and its spread in the world is one of the dominant trends in Korean studies. Koreans often identify Korean studies with the culture of Korea. At present, most Korean regional studies works are devoted to the study of Korea, ways to stimulate its regional and national development and solve the problem of uneven development of regions within the country.

\section{References}

1. E. V. Kremnyov, O. V. Kuznetsova, E. V. Lesnikovskaya, Transdisciplinary Regionology: Theory and Methodology (ISU, Irkutsk, 2020)

2. E. V. Kremnyov, E. V. Lesnikovskaya, O. V. Kuznetsova, Journal of SibFU. Humanities \& Social Sciences (Prepublication) Modern Transdisciplinary
Regionology: the Goal and the Objectives (2019) URL: http://elib.sfu-kras.ru/handle/2311/111803

3. W. Isard, Introduction to Regional Science (Englewood Cliffs, NJ.: Prentice-Hall, 1975)

4. A.M. Isserman, International Regional Science Review, The History, Status, and Future of Regional Science: An American Perspective, 3, 249-296 (1995)

5. K. Moskowitz, Journal of Asian Studies, Korean Development and Korean Studies A Review Article, 1, 63-90 (1982)

6. Technopolis. Best Practices for Science and Technology Cities (Springer-Verlag, London, 2014).

7. A. Saxenian, Regional Advantage: Culture and Competition in Silicon Valley and Route 128 (Harvard University Press, Cambridge, MA, 1994)

8. Joon-Kyo Seo, Land Use Policy, Balanced National Development Strategies: The Construction of Innovation Cities in Korea, 26, 649-661 (2009)

9. Lee Hyun-kyung, Kim Hong-bae, The Annals of Regional Science, Regional Preferences for the Living Environment and Mobility of Researchers and General Workers: the Case of Korea, 62, 169186 (2019)

10. A. O. Hirschman The Strategy for Economic Development (Yale University Press, New Haven, CT, 1958)

11. J. Friedmann Regional Development Policy: A Case Study of Venezuela (MIT Press, Cambridge, MA, 1966)

12. Kim Yong Woong, Cha Mi Sook, Habitat International, Korea's Spatial Development Strategies for an Era of Globalisation, 4, 531-551 (1994)

13. A. Bailly, L. J. Gibson, Papers in Regional Science, Regional Science: Directions for the Future, 83, 127-138 (2004)

14. Academy of Korean Studies. URL: http://intl.aks.ac.kr

15. B. Cumings, International organization, The Origins and Development of the Northeast Asian Political Economy: Industrial Sectors, Product Cycles, and Political Consequences, 38, 1-40 (1984) 